\title{
Pensononowoor
}

2019 , vol. $81,73-85$

http://dx.doi.org/10.12657/denbio.081.009

\section{Dynamics of epicotyl emergence of Quercus robur from different climatic regions is strongly driven by post-germination temperature and humidity conditions}

Received: 16 April 2019; Accepted: 25 July 2019

\begin{abstract}
Pedunculate oak (Quercus robur L.) is an important component of temperate forests in the northern hemisphere. It occurs naturally across Europe and in parts of North Africa, the Balkans, the Urals and the Caucasus. In Poland, it predominantly grows on the plains at $\leq 700 \mathrm{~m}$ a.s.l.

The main objective of this study was to determine how different temperature-humidity growth conditions influence dormancy breakage and epicotyl emergence in $Q$. robur, using growth curve models. We also investigated whether these differences result from changes in the climatic conditions under which the oak populations grow naturally.

In this study, we selected four pedunculate oak stands in western and eastern Poland. These sites were characterised by oceanic and continental climates, respectively. Mature acorns were collected in the autumn of 2016 and pretreated for two weeks in the cold $\left(4^{\circ} \mathrm{C}\right)$. The acorns were then sown in plastic pots filled with a peat/sand substrate. Four climatic variants (cold-dry, cold-wet, warm-dry and warm-wet) and a control (average conditions) were used. Epicotyl emergence was monitored daily for 74 days. Epicotyl emergence dynamics (maximum absolute growth rate, lag time, $T_{50}$ ), number of days to epicotyl emergence, and cumulative epicotyl emergence were measured or calculated.

The acorns from oceanic climates required more intense warm humid conditions for epicotyl emergence than those from continental climates. In contrast, acorns from continental climates had an evolutionary advantage in that their epicotyl emergence occurred both in cold-dry and warm-wet seasons. This indicated that each population was adapted to its local environment.
\end{abstract}

Keywords: epicotyl dormancy, Richards models, growth models, acorns, ecological niche

Addresses: Sz. Jastrzębowski, Department of Silviculture and Forest Tree Genetics, Forest Research Institute, 3 Braci Leśnej Str., 05-090 Raszyn, Poland, e-mail: s.jastrzebowski@ibles.waw.pl J. Ukalska, Biometry Division, Department of Econometrics and Statistics, Faculty of Applied Informatics and Mathematics, Warsaw University of Life Sciences, Nowoursynowska 159, 02-776 Warsaw, Poland, e-mail: joanna_ukalska@sggw.pl 


\section{Introduction}

The genus Quercus consists of 400 species taxonomically divided into three groups: red oak, white oak, and intermediate groups. The red oaks are found only in the western hemisphere, whereas the white oaks are widely distributed across the northern hemisphere. Many oak species occur in arid regions. Pedunculate oak (Q. robur L.) grows on heavier soils in continental climates and on wet lowlands and damp areas alongside streams and rivers; it tolerates periodic flooding (Eaton et al., 2016). Quercus robur has a wide climatic amplitude and grows well under oceanic and continental climate conditions. It is found further to the east, north, and south than Q. petraea.

Q. robur is an economically and ecologically important species in Europe (Annighöfer et al., 2015). Pedunculate oak in Europe has relatively few seed yield periods (Kantorowicz, 2000) because of the energetic expense associated with acorn production. Weather conditions during blooming and seed formation significantly influence seed yield intensity and progeny adaptability. An objective of the present study was to elucidate the adaptive changes in $Q$. robur and the relationship between its reproductive patterns and the environment. The biological properties of seeds depend on individual traits of trees as well as biotic and abiotic factors (Shelton \& Cain, 2000; Hilli et al., 2008). Temperature and water supply substantially affect seed formation and germination (Sahlén \& Bergsten, 1994).

In Poland, Q. robur occurs on the lowland. The maximum elevation is $400-500 \mathrm{~m}$ a.s.l. At the highest altitudes, Q. robur is deformed and grows poorly. In Poland, this species is mainly found on the Krotoszyn Plateau and in Lower Silesia, Odra Valley, and Lublin region. Oak species (Q. robur and Q. petraea) occur on less than $10 \%$ of the forested area in Poland (Anonymous, 2018) From the ecological and economical point of view oaks are the most important deciduous tree species after European beech (Fagus sylvatica L.) and birch (Betula pendula Roth.). The future role of this species will be increasing with forecasted climate change (Franklin et al., 2016). Unfortunately, the oaks in Central Europe seldom regenerate naturally. The reasons for this variability in natural oak regeneration are poorly understood despite intensive study (Ligot et al., 2013). One possible explanation is that the weather conditions are inappropriate and unsuitable for oak seed germination and tree regeneration.

Seed germination is a critical step in the plant life cycle; it determines their spread, evolution, and seasonal changes (Norden et al., 2009; Mondoni et al., 2012). The most favourable period for seed germination vary with species and geographic distribution (Vranckx \& Vandelook, 2012). Therefore, the study of seed behaviour in response to climate change is essential to understanding how and why it influences plant recruitment and species distribution (Donohue et al., 2010). Trait-based approaches have improved our understanding of plant evolution, community assembly, and ecosystem functioning (Saatkamp et al., 2019).

Dormancy facilitates spatiotemporal seed dispersal and may be induced by physical, mechanical, or chemical inhibition. Dormancy may temporally redistribute germination because environmental factors may be required to break dormancy (Bewley et al., 2013). Dormant seeds may be dispersed over long distances by wind, water, and animals; thus, seed dormancy could contribute to spatial distribution. Q. robur acorns are generally considered to be nondormant. In white oak (subgenus Lepidobalanus), the components of the embryonic axis in the acorn differ in terms of depth of physiological dormancy. In mature acorns, the radicle is nondormant, but the epicotyl is dormant (Baskin \& Baskin, 2001). Radicles emerge from the acorns immediately following autumn dispersal and taproots develop in autumn and early winter (Olson, 1974). In contrast, cold stratification is required to break acorn epicotyl dormancy (Farmer, 1977).

Germination (radicle and epicotyl emergence) is evaluated as the cumulative fraction of seeds $C G(t)$ geminating up to day $t$. These data are best represented by Richards family sigmoidal growth curves, characterised by an initial slow growth phase, followed by rapid growth reaching a maximum rate at the inflexion point. In the final stage, the growth rate decreases and converges to the upper asymptote. The perfect growth model should have the following features:

1. Parameters that can be directly interpreted empirically and affect only one shape characteristic (Tjørve \& Tjørve, 2010, 2017a, 2017b). This feature facilitates interpretation and supports the calculation of approximate standard errors or confidence intervals using statistical software. Initial parameter values must be entered when determining them using statistical software. However, it is difficult to estimate the initial values of these parameters if they have no biological significance (Zwietering et al., 1990).

2. Include parameters with the same significance in each applied model (Tjørve \& Tjørve, 2010, 2017b). This facilitates comparison of the estimated parameters between models and datasets.

These features apply to Richards family models. In recent years, Tjørve and Tjørve (2010, 2017a, 2017b) analysed them and proposed a family of unified sigmoidal growth models. In the present study, we implemented this approach but identified the essential parameters in each model, which account for epicotyl 
emergence dynamics. We focused on: 1, lag time (lag phase)-delay in the onset of epicotyl emergence; 2 , slope at inflexion-absolute maximum germination rate; 3 , time at inflexion; $4, T_{50}$-time at which $50 \%$ of the epicotyls emerge from the acorns; and 5, final proportion of epicotyl emergence proportion (epicotyl emergence capacity; upper asymptote).

In the present study, we aimed to demonstrate via growth curve models that different temperature-humidity growth conditions can influence dormancy breakage and epicotyl emergence dynamics. Additionally, we aimed to determine whether these differences are caused by the climatic conditions in which the oak populations grow. Another objective was to examine the variations in ecological amplitude width within populations of the same species growing under different climatic conditions. The findings of this study could have serious implications in terms of oak forest management, particularly in seed transfer and natural tree regeneration under the changing climate.

\section{Methods}

\section{Study area}

Four seed stands (two main and two auxiliary) were selected in Krotoszyn (KROT-51 $39^{\prime} \mathrm{N}, 17^{\circ} 30^{\prime} \mathrm{E}$ ) and Strzelce (STRZE-50 $50^{\circ} \mathrm{N}, 23^{\circ} 51^{\prime} \mathrm{E}$ ) in western and eastern Poland, respectively. The auxiliary stands were located near the main stands and were used in the case seed yields were low in the main stands. The annual average temperature in both study areas was $9.0{ }^{\circ} \mathrm{C}$. It approaches $15^{\circ} \mathrm{C}$ during the growing season (April-September) and $12.5^{\circ} \mathrm{C}$ during the epicotyl development phase (April-June). The annual precipitation ranges from $532 \mathrm{~mm}$ (KROT) to 550 mm (STRZE). According to the Köppen and Geiger climate classification system (Kottek et al., 2006), KROT has a temperate oceanic climate $(\mathrm{Cfb})$ with cool summers and warmer winters than other climates at this latitude. STRZE has a warm-summer humid continental climate (Dfb). Both seed stands had excellent phenotypic traits and belonged to one of the best $Q$. robur populations in Poland.

\section{Acorn collection and preparation}

Mature acorns were collected from the forest floor in the autumn of 2016 and originated from ten parent trees per main study area. A total of $3.82 \mathrm{~kg}(692$ acorns) were collected from KROT and $5.39 \mathrm{~kg}$ (866 acorns) were collected from STRZE. After harvest, the acorns were stored in paper bags at $4{ }^{\circ} \mathrm{C}$ for two weeks. Since the number of acorns was small, we tested seed viability before the experiment. Acorns were placed in sand and germinated at $20^{\circ} \mathrm{C}$ for two weeks. Only acorns with visible radicles (length $>$ 2-3 mm) were used in the subsequent experiments. Thereafter, acorns from each parent source were mixed and sown separately in plastic pots, which were then placed in growth chambers. Only one variant was tested per growth chamber. For each experiment, acorns were placed in $14 \mathrm{~cm}$ (height) $\times 9 \mathrm{~cm}$ (width) $\times 9 \mathrm{~cm}$ (length) plastic pots filled with peat/ sand substrate (2:1 ratio). Each pot was designated with a code (variant/origin/number of parent trees/ number of acorns). Each variant consisted of 60 seeds per population. The initial number of acorns for all variants was 600 .

\section{Epicotyl emergence experiment}

Here, the epicotyl emergence rate and total epicotyl emergence for different oak populations were determined under controlled conditions in growth chambers. The study was conducted at the Forest Research Institute from January to March 2017. Four variants (P1, P2, P3, and P4) and the control (P0) were prepared (Table 1) and epicotyl emergence was simulated under various climatic conditions. Temperature and precipitation characteristic of April (Stage 1), May (Stage 1), and June (Stage 3) were simulated under gradients of deviation (plus/minus) from the average conditions for these months (control). Stages 1 and 2 lasted 30 days and Stage 3 lasted two weeks. Precipitation was simulated by varying the amount of water used for irrigation which was calculated based on the average precipitation rates in KROT and STRZE (P0). We determined the volume of water (in millilitres) per pot per $24 \mathrm{~h}$ required to maintain the control level. For the other variants, dry

Table 1. Description of variants in growth chamber experiment; P0-P4 - variants of experiment

\begin{tabular}{|c|c|c|c|c|c|c|c|}
\hline \multirow[t]{2}{*}{ Variant } & \multicolumn{2}{|c|}{$\begin{array}{l}\text { Stage I: April conditions } \\
\text { (duration: } 30 \text { days) }\end{array}$} & \multicolumn{2}{|c|}{$\begin{array}{l}\text { Stage II: May conditions } \\
\text { (duration: } 30 \text { days) }\end{array}$} & \multicolumn{2}{|c|}{$\begin{array}{l}\text { Stage III: June conditions } \\
\text { (duration: } 14 \text { days) }\end{array}$} & \multirow[t]{2}{*}{ Description } \\
\hline & Temp. $\left({ }^{\circ} \mathrm{C}\right)$ & „Precip.” (ml/pot/24 h) & Temp. $\left({ }^{\circ} \mathrm{C}\right)$ & „Precip.” (ml/pot/24 h) & Temp. $\left({ }^{\circ} \mathrm{C}\right)$ & „Precip.” (ml/pot/24 h) & \\
\hline P0 & 8.2 & 10 & 13 & 14 & 16.7 & 15 & average \\
\hline $\mathrm{P} 1$ & 4.5 & 5 & 9 & 8 & 14 & 9 & cold-dry \\
\hline $\mathrm{P} 2$ & 4.5 & 15 & 9 & 23 & 14 & 23 & cold-wet \\
\hline P3 & 12 & 5 & 17 & 8 & 20 & 9 & warm-dry \\
\hline P4 & 12 & 15 & 17 & 23 & 20 & 23 & warm-wet \\
\hline
\end{tabular}


(P1 and P2) and wet (P3 and P4) growth conditions were simulated for April, May, and June.

Epicotyl emergence was monitored daily for 74 days and the number of post-germination days to epicotyl emergence was recorded. Epicotyls were considered to have emerged when the epicotyls were visible outside the pericarp. The experiment was terminated when no further epicotyl emergence was recorded.

\section{Statistical analysis}

\section{Growth models}

The logistic, Gompertz, and Richards growth models were applied in this study, with each model having two parameterisations. One considered the maximum absolute growth rate ( $\mu_{i}$ form) and was proposed by Ukalska and Jastrzębowski (2019), and the second considered lag time ( $T_{\lambda}$ form) and was proposed by Zwietering et al. (1990). $T_{50}$ was calculated using the formulas in Table 2.

Growth curves were estimated by the nonlinear least squares method according to the Levenberg-Marquardt algorithm (Marquardt, 1963). As the nonlinear least squares method is iterative, the appropriate initial values must be chosen for the model parameters so that the algorithm converges. To determine the crude initial values, a scatterplot of the growth data was applied to all tests, variants, and populations.

In nonlinear regression models, the nonlinear least squares estimators must be as effective as those for linear regression models. The estimators should be unbiased, normally distributed, and achieve the lowest variance. Nonlinear behaviour in model parameters is undesirable because the parameter estimates and their standards errors will be biased and cause erroneous inferences (Ratkowsky, 1983, 1990). Ratkowsky (1983) proposed the term "close-to-linear" for model estimators with the desired properties. To verify whether estimator behaviour is "close-to-linear", linearity measures such as Box's bias (b) (Box, 1971) and Hougaard's skewness (h) (Hougaard, 1982, 1985) were used.

For the "cold" variants (P1 and P2), sigmoidal growth curves were not fitted because epicotyl emergence was $<30 \%$ and did not reach the inflexion point. The dataset to which the growth curve model

Table 2. Parameterisations of sigmoidal growth models. $C G(t)$ : expected cumulative percentage germination at time $t$; $A$ : upper asymptote (theoretical maximum for $C G(t)$ ); $\mu i$ : maximum absolute growth rate or slope of the tangent at the inflection point; $T_{i}$ : time at an inflection $T_{\lambda}$ : lag time or delay in the onset of germination; $e$ : base of natural logarithms; m1-m6: models 1-6.

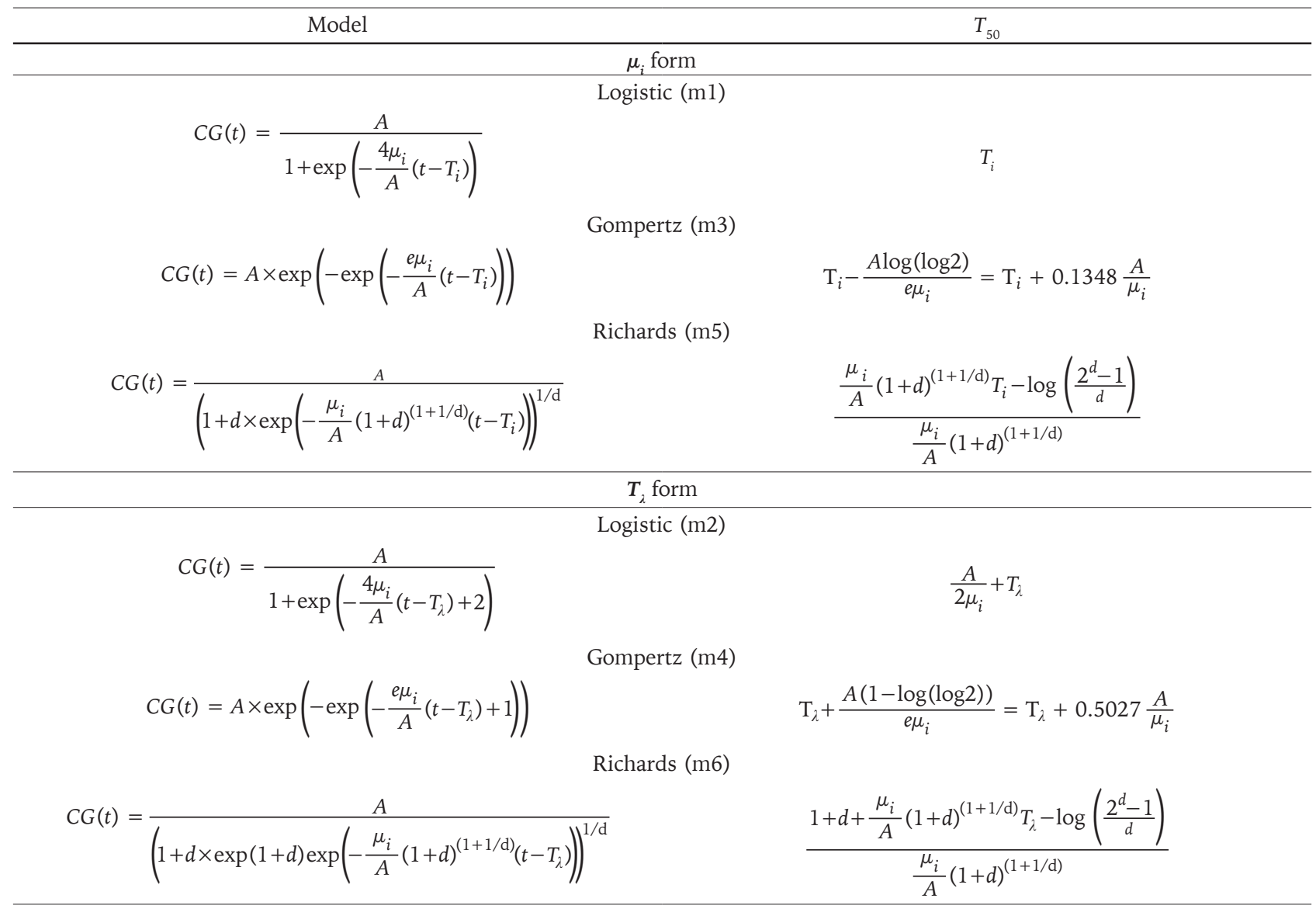


is fitted must cover the entire range for which the model applies or else the nonlinear least-squares estimators will be poor and nonlinear (Ratkowsky, 1993). Therefore, the epicotyl emergence growth curves were separately determined for the P0, P3, and $\mathrm{P} 4$ variants of the KROT and STRZE populations. However, the "cold" variants were presented descriptively. The growth curves for models 1-6 and metrics for nonlinear model parameters behaviour were obtained using the NLIN procedure of SAS/ STAT $^{\circledR}$ v. 14.3 (SAS Institute Inc., 2017).

\section{Number of days to epicotyl emergence (DEE)}

The number of days to epicotyl emergence (DEE) is a counted variable and can, therefore, be modelled by the Poisson distribution. To test the effects of population and variants on $D E E$, a generalised linear model (GzLM) was used:

$$
\mathrm{g}\left(\text { DEE }_{i j}\right)=\text { Population }_{i}+\text { Variant }_{j}+\text { Population }_{i} \times
$$

where $\mathrm{g}\left(D E E_{i j}\right)$ is a log link function, $D E E_{i j}$ is the expected mean of number of days to epicotyl emergence for the $i$-th population in the $j$-th variant, Population $_{i}$ is the main effect of the $i$-th population, Variant is the main effect of the $j$-th variant and Population $_{i} \times$ Variant $_{j}$ is the interaction effect. The significance of the model effects was evaluated by the Wald $\chi^{2}$ test for a type 3 analysis. For significant model effects, pairwise comparisons were made between leastsquare means with Tukey's post-hoc test and the Tukey-Kramer correction for unequal sample sizes. All calculations were performed using the GENMOD procedure of SAS/STAT ${ }^{\circledR}$ v. 14.3 (SAS Institute Inc., 2017).

\section{Cumulative epicotyl emergence (CEE)}

Diversity between populations and the effects of the variants on CEE (dichotomous variable: 1-epicotyl appeared; 0-no epicotyl) were tested with two generalised linear models. In the first model, all variants were considered and a GzLM was used:

$$
\mathrm{g}\left(\mathrm{CEE}_{i j}\right)=\text { Population }_{i}+\text { Variant }_{j}
$$

where $\mathrm{g}\left(C E E_{i j}\right)$ is the logit link function and $C E E_{i j}$ is the expected mean of emerged epicotyls for the $i$-th population in the $j$-th variant. Definitions for all other terms are the same as those for model 7 . The interaction effect was omitted in model 8 due to the lack of convergence in the full model. One possible reason was zero epicotyl emergence in P1 for KROT. Variants 0,3 and 4 were also analysed according to the full GzLM model (m9), which did consider the interaction effect.

The significance of the model effects and pairwise comparisons was determined according to the methods described in Subsection Number of days to epicotyl emergence (DEE). All calculations were performed using the GENMOD procedure of SAS/ STAT $^{\circledR}$ v. 14.3 (SAS Institute Inc., 2017).

\section{Results}

\section{"Cold" variants}

For the variant P1 (cold-dry), the cumulative epicotyl emergence reached its maximum of $28.6 \%$ after 68 days with acorns from STRZE. Moreover, it did not change until the end of the experiment (Fig. 1). The first epicotyls appeared during the first phase of

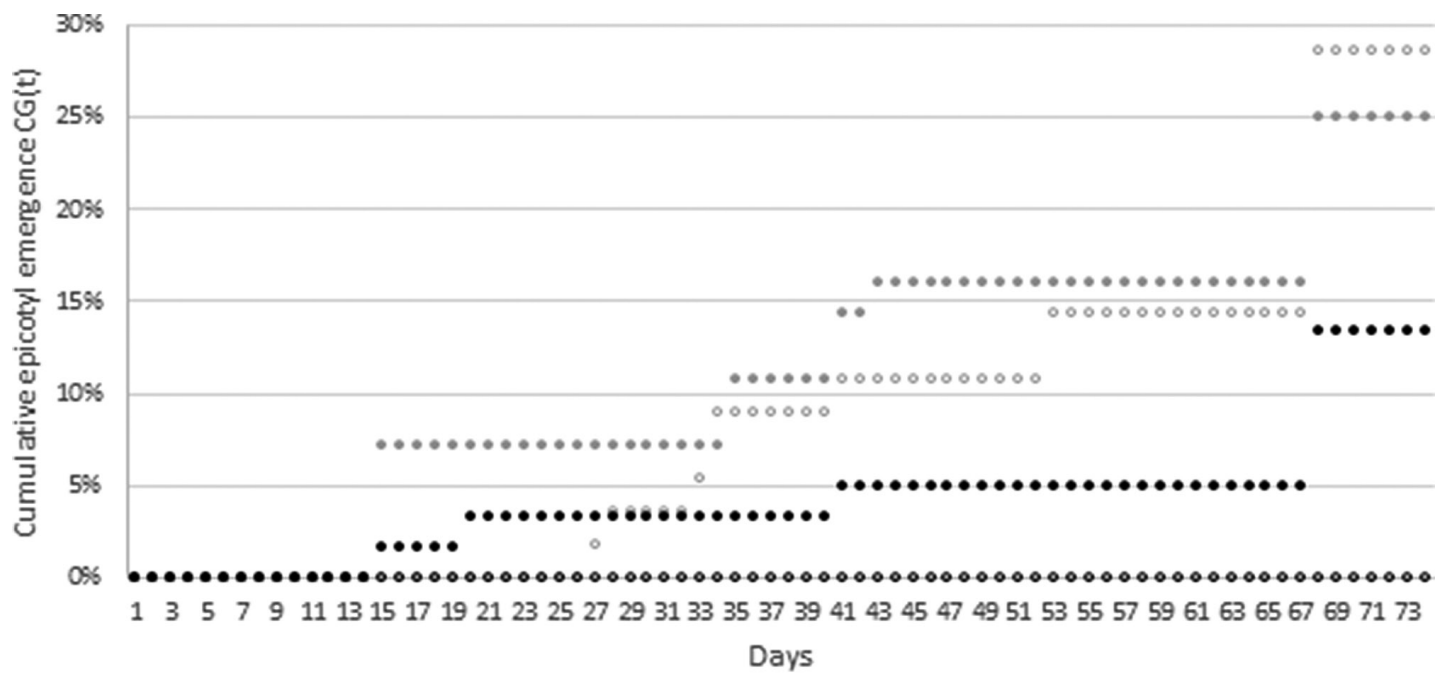

-STRZEP1 • STRZEP2 •KROTP1 • KROTP2

Fig. 1. Epicotyl emergence in variants P1 (cold-dry) and P2 (cold-wet) of the STRZE (grey full and empty circles) and KROT (black full and empty circles) populations 
the experiment (after 28 days $-1.8 \%$ ) when the temperature $(\mathrm{T})$ was $4.5^{\circ} \mathrm{C}$ and the "precipitation" $(\mathrm{P})$ was $5 \mathrm{~mL} 24 \mathrm{~h}^{-1}$ per pot. However, most of the epicotyls appeared after 41 days $\left(\mathrm{T}=9{ }^{\circ} \mathrm{C} ; \mathrm{P}=8 \mathrm{~mL} 24\right.$ $\mathrm{h}^{-1}$ per pot). No epicotyls emerged from the KROT acorns under these conditions (Fig. 1). For the variant P2 (cold-wet), epicotyls emerged from both the KROT and STRZE acorns. Epicotyls appeared in both populations simultaneously (15 days after the start of the experiment). Nevertheless, $7.1 \%$ of the STRZE population showed epicotyl emergence, whereas only $1.6 \%$ of the KROT acorns presented with epicotyls. After 41 days (second stage of the experiment), $14.3 \%$ of the STRZE acorns had developed epicotyls as opposed to only $5 \%$ of the KROT acorns. At the end of the experiment (after 74 days), total epicotyl emergence was higher in the STRZE than the KROT acorns (25.0\% and $13.3 \%$, respectively).

\section{Growth models-goodness of fit}

The Table 3 presents the Akaike (corrected due to number of model parameters - AIC , Burnham \& Anderson, 2002) and Bayesian BIC (Schwarz, 1978) information criteria calculated for all growth models of the populations and variants in the present study. Both information criteria clearly indicated the logistic model for P0 and P3 of KROT and P4 of STRZE and the Richards model for P0 and P3 of STRZE. For the P4 of KROT, the smallest BIC was for the logistics model and the smallest $\mathrm{AIC}_{\mathrm{C}}$ for the Richards model. In this case, the choice of the model was made based not only on information criteria, but also on the linearity measures of the model parameter estimates. For the Richards model, Hougaard's skewness for parameter $d$ estimator exceeded $0.4(d=0.43$, data not shown) which indicates 'moderate' nonlinearity. Moreover, the approximate $95 \%$ confidence interval for parameter $d$ includes $d=1$ (Table 4 ), which means that the Richards model can be simplified to the logistic model. For the logistic model, the Hougaard's skewness for the parameter $\mu_{i}$ slightly exceeded 0.16 , which even under the more rigorous conditions than those given by Ratkowsky (1983), proposed by Haines at al. (2004) indicated "close-to-linear" behaviour. For all models and datasets, the acceptance level was $P<0.001$ (results not shown).

To assess the parameters estimation efficiency for each model chosen according to the $\mathrm{AIC}_{\mathrm{C}}$ and
BIC values, Hougaard's measure of skewness $h$, and Box's measure of bias $b$ were determined separately for each model (Table 4). For almost all parameters of the models tested, $|h| \leq 0.25$. Therefore, according to the rule proposed by Ratkowsky (1983) these parameters exhibited "close-to-linear" behaviour. Haines et al. (2004) suggested very rigorous amendment Ratkowsky's rule-of-thumb that the parameter estimate is reasonably close-to-linear if the absolute value of $h$ does not exceed 0.15. In the recent time Ratkowsky (2017) proposed a compromise cut-off criterion, where the absolute value of the skewness measure $|h| \leq 0.2$ indicates "good" behaviour, $0.2<$ $|h| \leq 0.5$ indicates "moderate" nonlinearity and $|h|$ $>0.5$ indicates "bad", that is, far-from-linear behaviour. Applying this compromise rule, three parameters of the models presented in Table 4 indicated "moderate" nonlinearity, while the other parameters indicated "good", that is, linear behaviour.

Box's bias for the close-to-linear parameter estimator should not exceed 1\% (Ratkowsky, 1983). Box's bias values slightly exceeding 1 were found for parameter $d$ in the Richards models of STRZE P0 and STRZE P3. For all other parameters, $b$ was $<1 \%$, which indicated that they had "close-to-linear" behaviour (Table 4).

\section{Rate of epicotyl emergence (maximum absolute growth rate; lag time; $T_{50}$ )}

The maximum absolute growth rate of epicotyl emergence $\left(\mu_{i}\right)$ for the variant P0 (control) did not differ among populations $\left(\mu_{i}=4 \%\right)$ (Table 4; Fig. 2a). However, the population did differ in terms of the time at which $\mu_{i}$ was achieved $\left(T_{i}\right)$. Acorns from STRZE reached $\mu_{i}$ after $T_{i}=34.7$ days followed by KROT after $T_{i}=46.5$ days. The difference in time of onset of intensive epicotyl emergence (lag time, $T_{\lambda}$ ) in the control variant was $\sim 10$ days (STRZE $T_{2}=$ 25.9 days; KROT $T_{\lambda}=35.7$ days). The maximum absolute growth rate of epicotyl emergence did not different among populations $\left(\mu_{i}=6 \%\right)$ for the variants P3 (warm-dry) and P4 (warm-wet) but was attained sooner in them than the control variant (P0) (Table 4; Fig. 2a-c). For the KROT acorns, the time required to reach the maximum absolute growth rate of epicotyl emergence differed by 11.4 days (P0 vs. P3) and 15 days (P0 vs. P4). The difference between P3

Table 3. $\mathrm{AIC}_{\mathrm{C}}$ and BIC information criteria for fitted growth models. The model with the lowest $\mathrm{AIC}_{\mathrm{C}}$ and BIC (in bold) was selected for each variant and population (KROT - Krotoszyn, STRZE - Strzelce)

\begin{tabular}{|c|c|c|c|c|c|c|c|c|c|c|c|c|}
\hline \multirow{2}{*}{$\begin{array}{l}\text { Growth } \\
\text { model }\end{array}$} & \multicolumn{2}{|c|}{ PO KROT } & \multicolumn{2}{|c|}{ P0 STRZE } & \multicolumn{2}{|c|}{ P3 KROT } & \multicolumn{2}{|c|}{ P3 STRZE } & \multicolumn{2}{|c|}{ P4 KROT } & \multicolumn{2}{|c|}{ P4 STRZE } \\
\hline & $\mathrm{Cr}_{0}$ & & $\mathrm{ICc}$ & $\overline{\text { RI }}$ & $\mathrm{Cc}$ & & $\mathrm{ICc}$ & $\mathrm{BIC}$ & $\mathrm{Cc}$ & $\mathrm{BIO}$ & $\mathrm{ICc}$ & BIC \\
\hline oictic & & & & 518 & & & & 0 & & & 12 & \\
\hline & 7.59 & -409 & -209.37 & -521.30 & 75 & -2 & -1 & -474 & -1 & -4 & 57 & -4 \\
\hline ichards & not con & iverged & -214.00 & -523.86 & -205.78 & -515.65 & -208.24 & -518.10 & -210.77 & -520.64 & -178.88 & -488.75 \\
\hline
\end{tabular}


and P4 was only 3.6 days. KROT and STRZE acorns in the variant $\mathrm{P} 3$ needed 35.1 and 32.2 days, respectively, to achieve $\mu_{i}$. For the variant P4, the acorns achieved $\mu_{i}$ earlier than those for P3. Epicotyl emergence occurred $\sim 4$ days earlier in STRZE $\left(T_{i}=27.3\right.$ days) than in KROT ( $T_{i}=31.5$ days $)$. The KROT acorn lag time was shorter for variants $\mathrm{P} 3$ and $\mathrm{P} 4\left(T_{\lambda}\right.$ $=27.9$ days and $T_{2}=24.2$ days, respectively) than
P0 $\left(T_{2}=35.7\right.$ days $)$. The differences in KROT acorn epicotyl emergence lag time between the control and the other variants were 7.8 days (P0 vs. $\mathrm{P} 3$ ) and 11.5 days (P0 vs. P4). For the STRZE acorns, the lag time was shorter for P3 and P4 $\left(T_{2}=23.8\right.$ days and $T_{\lambda}$ $=19.0$ days, respectively). STRZE acorns also had a shorter lag time for all variants than those from KROT (P0 vs. P3, 2.1 days; P0 vs. P4, 7 days).

Table 4. Parameter estimates of chosen according to BIC and $\mathrm{AIC}_{\mathrm{C}}$ values growth models; standard errors (SE) and confidence intervals; measures of model adequacy; and derived time T50 (KROT - Krotoszyn, STRZE - Strzelce)

\begin{tabular}{|c|c|c|c|c|c|c|}
\hline Parameter & Estimate & Approximated SE & Approximate & dence limits & Skewness $|h|$ & Percent Bias $b$ \\
\hline \multicolumn{7}{|c|}{$\mathrm{P} 0$} \\
\hline KROT & Logistic & & & & & \\
\hline$A$ & 0.941 & 0.016 & 0.909 & 0.973 & 0.12 & 0.05 \\
\hline$\mu_{i}$ & 0.044 & 0.002 & 0.039 & 0.048 & 0.24 & 0.32 \\
\hline$T_{i}$ & 46.460 & 0.404 & 45.654 & 47.266 & 0.07 & 0.02 \\
\hline$T_{\lambda}$ & 35.671 & 0.616 & 34.444 & 36.899 & 0.07 & 0.01 \\
\hline$T_{50}$ & 46.460 & & & & & \\
\hline STRZE & Richards & & & & & \\
\hline$A$ & 0.914 & 0.007 & 0.899 & 0.929 & 0.12 & 0.03 \\
\hline$\mu_{i}$ & 0.045 & 0.001 & 0.042 & 0.048 & 0.13 & 0.23 \\
\hline$d$ & 0.410 & 0.170 & 0.071 & 0.749 & 0.19 & 1.08 \\
\hline$T_{i}$ & 34.665 & 0.575 & 33.518 & 35.811 & 0.12 & 0.04 \\
\hline$T_{\lambda}$ & 25.870 & 0.349 & 25.175 & 26.566 & 0.00 & 0.05 \\
\hline$T_{50}$ & 36.044 & & & & & \\
\hline \multicolumn{7}{|c|}{ P3 } \\
\hline KROT & Logistic & & & & & \\
\hline$A$ & 0.905 & 0.005 & 0.894 & 0.915 & 0.01 & 0.01 \\
\hline$\mu_{i}$ & 0.063 & 0.002 & 0.059 & 0.068 & 0.16 & 0.14 \\
\hline$T_{i}$ & 35.072 & 0.156 & 34.760 & 35.384 & 0.00 & 0.00 \\
\hline$T_{\lambda}$ & 27.942 & 0.291 & 27.362 & 28.522 & 0.05 & 0.00 \\
\hline$T_{50}$ & 35.072 & & & & & \\
\hline STRZE & Richards & & & & & \\
\hline$A$ & 0.924 & 0.005 & 0.913 & 0.934 & 0.03 & 0.01 \\
\hline$\mu_{i}$ & 0.062 & 0.002 & 0.057 & 0.066 & 0.23 & 0.30 \\
\hline$d$ & 1.739 & 0.328 & 1.084 & 2.394 & 0.46 & 1.47 \\
\hline$T_{i}$ & 32.186 & 0.445 & 31.300 & 33.073 & 0.02 & 0.00 \\
\hline$T_{\lambda}$ & 23.777 & 0.386 & 23.008 & 24.547 & 0.06 & 0.06 \\
\hline$T_{50}$ & 31.277 & & & & & \\
\hline \multicolumn{7}{|c|}{ P4 } \\
\hline KROT & Logistic & & & & & \\
\hline$A$ & 0.857 & 0.005 & 0.847 & 0.867 & 0.01 & 0.01 \\
\hline$\mu_{i}$ & 0.059 & 0.002 & 0.054 & 0.063 & 0.16 & 0.14 \\
\hline$T_{i}$ & 31.473 & 0.163 & 31.147 & 31.798 & 0.00 & 0.00 \\
\hline$T_{\lambda}$ & 24.172 & 0.306 & 23.562 & 24.781 & 0.05 & 0.00 \\
\hline$T_{50}$ & 31.473 & & & & & \\
\hline STRZE & Logistic & & & & & \\
\hline$A$ & 0.996 & 0.006 & 0.984 & 1.008 & 0.01 & 0.01 \\
\hline$\mu_{i}$ & 0.060 & 0.002 & 0.055 & 0.064 & 0.17 & 0.14 \\
\hline$T_{i}$ & 27.285 & 0.184 & 26.920 & 27.651 & 0.00 & 0.00 \\
\hline$T_{\lambda}$ & 18.953 & 0.342 & 18.270 & 19.635 & 0.05 & 0.00 \\
\hline$T_{50}$ & 27.285 & & & & & \\
\hline
\end{tabular}



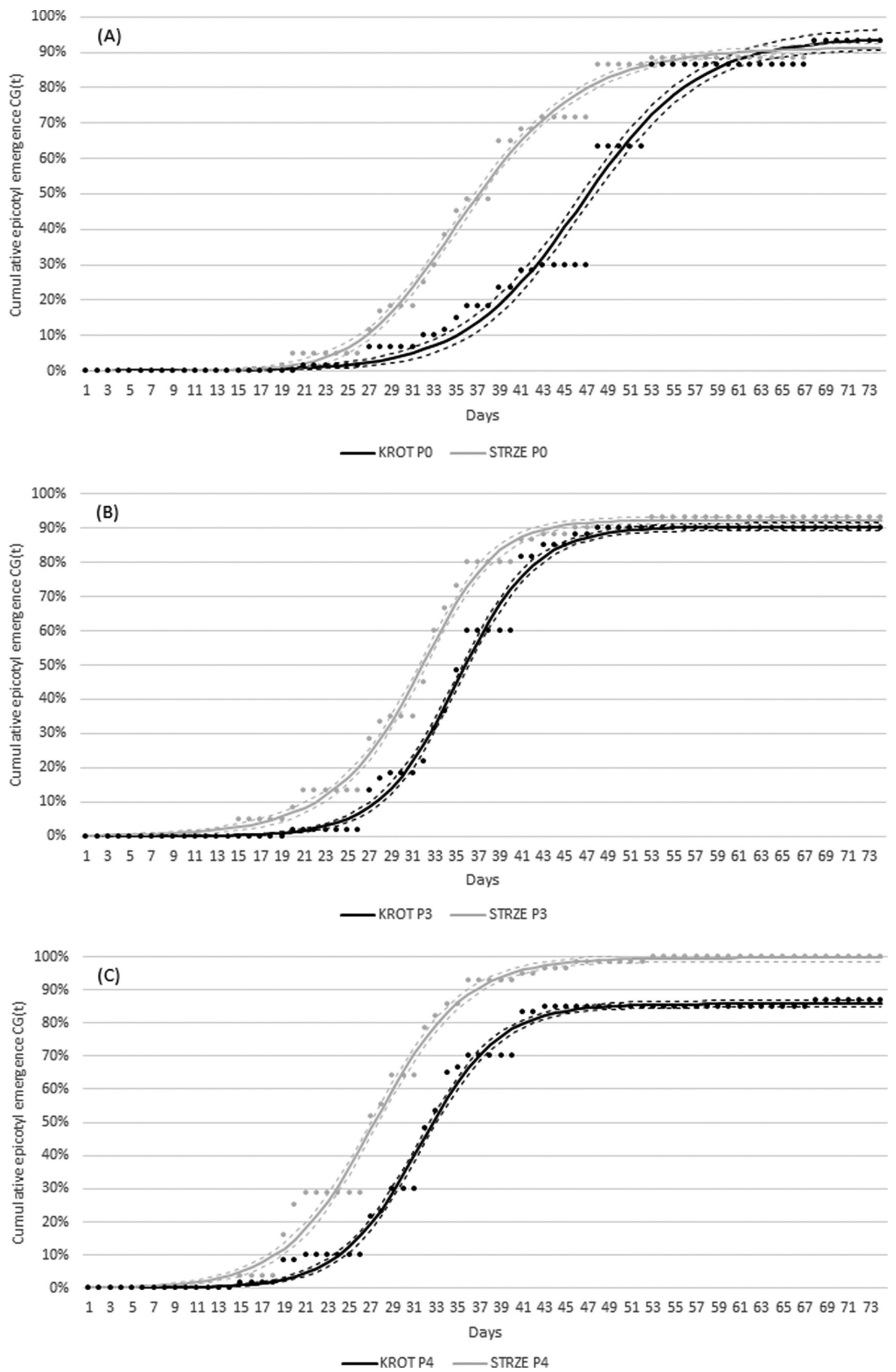

Fig. 2. Fitted Richards family growth curves and experimental data describing the dynamics of pedunculate oak epicotyl emergence for the variants P0 (control) (A), P3 (warm-dry) (B), and P4 (warm-wet) (C); STRZE - grey line; KROT black line 
The time until $50 \%$ epicotyl emergence $\left(T_{50}\right)$ was determined from the best-fit growth functions (Table 4). For the variant P0 of the STRZE acorns, $T_{50}$ was observed 10.5 days earlier than it was for the KROT acorns (36.0 days and 46.5 days, respectively). The differences between populations were relatively smaller for the warmer variants P3 and P4 (3.8 days and 4.3 days, respectively) but the differences between variants within the same population were highly distinct. KROT acorns in the warm and dry variant (P3) reached $T_{50} 11.4$ days earlier than the control (35.1 days). For the warm and wet variant (P4), $T_{50}$ arrived 15 days earlier than the control (31.6 days). For the STRZE acorns, these differences were comparatively smaller (P3 vs. P0: 4.7 days ; P4 vs. P0: 8.7 days).

\section{Number of days to epicotyl emergence (DEE)}

Model 7 was used to assess the effects of population, variants and their interaction on the number of days to epicotyl emergence, DEE. All effects were significant (Table 5).

For the STRZE population, the mean number of days needed for epicotyl emergence (DEE) $<$ that for the KROT population (Table 6). This relationship was confirmed for the P0 (control), P3 and P4 variants in both populations. For the "cold" variants (P1 and P2); however, these differences were not confirmed. Considering the total mean for all variants (last column of Table 6), P4 had the lowest DEE followed by P3 and P0. Regarding DDE, P1 and P2

Table 5. Results of the generalised linear model testing the differences in the number of days to epicotyl emergence DEE associated with population, variant and interactions between them. A Wald test was used in a type 3 analysis. DF: degrees of freedom; P: probability

\begin{tabular}{lcrc}
\hline \multicolumn{1}{c}{ Effect } & DF & Chi-Square & \multicolumn{1}{c}{ P } \\
\hline Population & 1 & 49.11 & $<0.001$ \\
Variant & 4 & 2720.09 & $<0.001$ \\
Population $\times$ Variant & 4 & 24.27 & $<0.001$ \\
\hline
\end{tabular}

variants did not significantly differ. For DEE of the "warm" variants (P3 and P4), no significant differences were observed within the KROT population.

\section{Cumulative epicotyl emergence (CEE)}

After 74 days, total epicotyl emergence was $>90 \%$ for the P0, P3, and P4 variants. For the variants P1 and P2, however, $<30 \%$ of the epicotyls had emerged. According to model 8, significant differences were found among the populations and variants in terms of epicotyl emergence (Table 7). The cumulative epicotyl emergence CEE for the STRZE population was significantly higher $(80 \%)$ than that for the KROT population (64\%). Two homogeneous groups were identified. One consisted of both "cold" variants (P1 and P2) and the other comprised the "warm" variants (P3 and $\mathrm{P} 4)$ and the control (P0). The results confirmed that the analysis accounted only for the warm variants and the control. For model 9, (Table 7), no significant differences were detected among populations, variants or their interactions.

Table 7. Results of a Wald test according to a type 3 analysis testing differences in cumulative epicotyl emergence $C E E$ associated with population and variants considering all variants (model 8, part A); and population, variants and their interactions considering variants 0 , 3 and 4 (model 9, part B). DF: degrees of freedom; P: probability

\begin{tabular}{|c|c|c|c|c|c|c|}
\hline \multirow[b]{2}{*}{ Effect } & \multicolumn{3}{|c|}{ A } & \multicolumn{3}{|c|}{ B } \\
\hline & $\mathrm{DF}$ & $\begin{array}{c}\text { Chi- } \\
\text { Square }\end{array}$ & $\mathrm{P}$ & $\mathrm{DF}$ & $\begin{array}{c}\text { Chi- } \\
\text { Square }\end{array}$ & $\mathrm{P}$ \\
\hline Population & 1 & 12.837 & $<0.001$ & 1 & 1.043 & 0.307 \\
\hline Variant & 4 & 224.492 & $<0.001$ & 2 & 0.621 & 0.733 \\
\hline $\begin{array}{l}\text { Population } \\
\times \text { Variant }\end{array}$ & - & - & - & 2 & 0.621 & 0.733 \\
\hline
\end{tabular}

\section{Discussion}

The application of Richards family growth curves to analyse epicotyl emergence dynamics is very useful for three reasons. First, the parameters of the logistic, Gompertz and Richards models (models m1-m6;

Table 6. Mean number of days to epicotyl emergence DEE associated with populations variant and their interactions. Means with the same lowercase letters within a row or means with the same uppercase letter within a column are not significantly different at P $\leq 0.05$; SE: standard error of the mean; KROT: Krotoszyn population; STRZE: Strzelce population; P0-P4: experimental variants

\begin{tabular}{cccc}
\hline & & Mean \pm SE & Total for Variants \\
\hline Variants & KROT & STRZE & $42.56 \pm 0.72 \mathrm{C}$ \\
P0 & $47.36 \pm 1.08 \mathrm{bB}$ & $38.25 \pm 0.97 \mathrm{aC}$ & $72.87 \pm 0.93 \mathrm{D}$ \\
P1 & $74 \pm 1.3 \mathrm{aC}$ & $71.76 \pm 1.34 \mathrm{aD}$ & $71.62 \pm 0.93 \mathrm{D}$ \\
P2 & $72.91 \pm 1.31 \mathrm{aC}$ & $70.34 \pm 1.31 \mathrm{aD}$ & $33.49 \pm 0.65 \mathrm{~B}$ \\
P3 & $35.44 \pm 0.95 \mathrm{bA}$ & $31.64 \pm 0.88 \mathrm{aB}$ & $29.53 \pm 0.60 \mathrm{~A}$ \\
P4 & $31.53 \pm 0.86 \mathrm{bA}$ & $27.65 \pm 0.83 \mathrm{aA}$ & \\
\hline
\end{tabular}


Table 2), namely, $\mu i, T_{i}, T$, and $A$, explained the maximum absolute growth rate, time at inflection, lag time, and cumulative epicotyl emergence, respectively. This method facilitated direct interpretation of all model parameters (Tjørve \& Tjørve, 2010, 2017b; Vrána et al., 2019; Ukalska \& Jastrzębowski, 2019). $T_{50}$ could be determined according to the estimated parameters of the models m1-m6 (Table 2). Second, when analysing dataset using parametrisations, taking in to account the same parameters from various Richards family growth models we have opportunity to compare the results directly across all models (Tjørve \& Tjørve, 2010, 2017b; Vrána et al., 2019). Third, use of growth model parametrisation describing the properties of the phenomena enables the calculation of approximated standard errors and confidence intervals for the estimated parameters directly from the model (Zwietering et al., 1990; Ukalska \& Jastrzębowski, 2019). However, even a model containing biologically meaningful but biased, "far-to-linear" parameter estimators has no practical value (Ratkowsky, 1993). Therefore, it is necessary to fit more than one growth model to the dataset being analysed to choose the best model (Tjørve \& Tjørve, 2017b). This objective can be accomplished by using U-Richards family models.

Temperate deciduous forests have wide temperature ranges at which seeds germinate (from $5 / 1^{\circ} \mathrm{C}$ for Sorbus aucuparia to $32 / 24{ }^{\circ} \mathrm{C}$ for Liquidambar styracifl$u$ a). Under laboratory conditions, $Q$. robur acorns usually germinate to a high percentage at $20^{\circ} \mathrm{C}$ (Suszka, 2006). Certain postharvest acorns germinate better at lower temperatures $\left(16^{\circ} \mathrm{C}\right)$, which suggests the presence of a specific inhibitory factor, which disappears after several months of storage at $-1{ }^{\circ} \mathrm{C}$. Expansion of the range of temperatures that aid germination is dormancy breakage (Suszka et al., 1996). For certain species, cold stratification may lower the minimum germination temperature. For instance, it reduces the seed germination temperatures for Betula populifolia seeds from $32{ }^{\circ} \mathrm{C}$ to $15^{\circ} \mathrm{C}$ (Joseph, 1929) and Alnus glutinosa seeds from $18{ }^{\circ} \mathrm{C}$ to $7{ }^{\circ} \mathrm{C}$ (McVean, 1955). Cold stratification also may change the germination light requirement (Baskin \& Baskin, 2001). Different temperature ranges initiate radicle and epicotyl growth. The radicle starts to develop at $5{ }^{\circ} \mathrm{C}$, whereas a temperature of $\geq 10{ }^{\circ} \mathrm{C}$ is necessary for the epicotyl to start emerging (Suszka et al., 1996).

Quercus robur seeds are recalcitrant; they die if their moisture content drops below a critical level (40-45\%). According to Suszka (2006), acorn embryos with the highest germination capacity and development have an average moisture level of $43 \%$. If the moisture content falls to $<40 \%$, the acorns gradually lose their ability to germinate. At moisture levels $<22 \%$, the germination rate in white oaks is only $6.0 \%$ and the epicotyl emergence rate is only $3.0 \%$.
Therefore, soil moisture levels are critical in determining seed germination. Acorns must be protected from desiccation, low temperatures and predation by insects, rodents and other animals in order to survive the winter. As acorns tend to fall in the autumn before or during leaf fall, they are usually protected from desiccation and freezing. Thick snow cover during the winter also protects acorns (Johnson et al., 2009).

According to KLIMADA, a climate change adaptation project (Polish National Strategy for Adaptation to Climate Change, 2013), winter temperatures expected for $2021-2050$ are projected to rise by $2.5{ }^{\circ} \mathrm{C}$ and $4.5{ }^{\circ} \mathrm{C}$ between 2071 and 2100 , especially in the northeastern part of Poland. This anticipated increase in winter temperature may occur globally and is projected to rise from $1.5^{\circ} \mathrm{C}(2021-2050)$ to $3.5^{\circ} \mathrm{C}$ (2071-2100).

The interruption of epicotyl dormancy of the continental oak population (STRZE) at lower temperatures is an example of natural selection. This process separates varieties and maintain evolutionary distance even among varieties which do not directly influence each other and never competed. Under conditions optimal for epicotyl growth, both populations rapidly develop epicotyls and present with high percentages of total epicotyl emergence. The continental population has a slight advantage over the oceanic population. When both populations grow close to each other and are under the same environmental conditions, they will probably respond to climate change in a similar manner. This situation may change when epicotyl dormancy is broken under inappropriate conditions such as cold-dry or cold-wet. According to the results of the present study, there are two different climatic varieties of $Q$. robur in Poland.

Adaptation of the epicotyl growth of the continental population (STRZE) to nonoptimal climate conditions and predominance of this variety under optimal conditions indicate that it has an evolutionary advantage over the oceanic KROT population. STRZE oaks can break acorn epicotyl dormancy under a wide range of environmental conditions. Therefore, they can occupy both their own ecological niche as well as that of KROT oaks.

Notably, continental STRZE oak acorn epicotyls emerge and develop under conditions optimal both for continental and oceanic populations. The relative lack of natural regeneration in the KROT oak has been observed for many years (Nowakowska et al., 2007); however, the mechanisms are poorly understood. Causative factors may include episodic drought, low groundwater levels, and thick litter layers (Filipiak \& Zaradny, 1991; Oszako, 2007). The findings of the present study suggest that low air (or soil) temperature during epicotyl emergence may be another explanatory factor. Under this condition, 
epicotyl dormancy is not broken and the acorns are susceptible to desiccation and rodent predation. This hypothesis requires further investigation.

In natural environments, epicotyl dormancy in Q. robur delays its development until conditions are favourable for seedling establishment. The optimal temperatures and durations for cold stratifaction in acorns are unknown. It is only known that the epicotyl requires cold exposure (winter) before springtime emergence whereas acorns sown in the spring develop normal seedlings after overwintering. Under controlled conditions, $Q$. robur acorns harvested in autumn can germinate and their epicotyls will emerge without winter chilling (unpublished data).

Global warming may shift the phenological requirement of germination for cold stratification (Walck et al., 2011). Seedling emergence will be delayed if the current cold stratification period satisfies the minimum requirement. On the other hand, if the current stratification period exceeds the required minimum, epicotyl emergence will start relatively early. The effects of global warming on stratification may vary among species dependent on the ranges of temperature and moisture level which may result in dormancy loss (Walck et al., 2011). The present study shows that intraspecies diversity may also occur. Elucidation of oak seedling development may help determine seed transfer directions and limits. Moreover, consideration of the ecological requirements of seeds may also improve the success of natural regeneration.

Our results suggest that $Q$. robur progeny are well-adapted to current local climatic conditions and are also adapted to a wide range of minimum temperatures required to break epicotyl dormancy. This adaptability is especially evident in the population originating from eastern Poland and under the influence of a continental climate. STRZE acorns may benefit from warming if winter temperatures exceed the minimum required for epicotyl emergence. Their reaction threshold is much lower than that of the acorns from KROT (oceanic climate). Therefore, epicotyl emergence can start earlier and faster in STRZE acorns. In view of climate change, it is important to select the appropriate seed sources for long-lived species such as oaks. These progeny must be well-suited to future environmental conditions and amenable to seed transfer. Our results suggest also that all analysed models are useful for study about germination of seed, in the case of dormant seed especially. Based on the data presented in this study, we believe that the considered growth models from the Richards family are a useful tool for studying the dynamics of not only the epicotyl emergence of oak, but can be successfully used to study the germination dynamics of other forest tree species (deciduous and coniferous). We intend to using this approach in our next studies about germination behaviour of seed.

\section{Acknowledgements}

The authors acknowledge Jerzy Przyborowski and Władysław Kantorowicz for help in acorns collecting and experiment preparing. We are also very grateful Forest Districts Strzelce and Krotoszyn for the availability of tree stands for our research.

Founding: This project (260202) was founded by Forest Research Institute in Poland (IBL) within the framework of the Research Found.

\section{References}

Anonymous (2013) Polish national strategy for adaptation to climate change. Ministry of the Environment.

Anonymous (2018) Raport o stanie lasów w Polsce. CILP, Warszawa.

Annighöfer P, Beckschäfer P, Vor T \& Ammer C (2015) Regeneration patterns of European oak species (Quercus petrae (Matt.) Liebl., Quercus robur L.) in dependence of environment and neighborhood. PLoS ONE 10: e0134935. doi:10.1371/ journal.pone.0134935.

Baskin CC \& Baskin JM (2001) Seeds. ecology, biogeography, and evolution of dormancy and germination. Academic Press, USA/UK.

Bewley JD, Bradford K, Hilhorst HWM \& Nonogaki H (2013) Seeds: Physiology of development, germination and dormancy. 3rd ed. Springer-Verlag, New York.

Box MJ (1971) Bias in nonlinear estimation. Journal of the Royal Statistical Society, Series B 33: 171-190.

Burnham KP \& Anderson DR (2002) Model selection and multimodel inference: a practical information-theoretical approach. 2nd ed. Springer-Verlag, New York.

Donohue K, de Casas RR, Burghardt L, Kovach K \& Willis C (2010) Germination, postgermination adaptation, and species ecological ranges. Annual Review of Ecology, Evolution and Systematics 41: 293-319. doi:10.1146/annurev-ecolsys-102209-144715.

Eaton E, Caudullo G, Oliveira S \& de Rigo D (2016) Quercus robur and Quercus petraea in Europe: distribution, habitat, usage and threats: European atlas of forest tree species (ed. by J San-Miguel-Ayanz, D de Rigo, G Caudullo, T Houston Durrant \& A Mauri) Publications Office of the European Union, Luxembourg.

Farmer RE Jr (1977) Epicotyl dormancy in white and chestnut oaks. Forest Science 23: 329-332.

Filipiak T \& Zaradny S (1991) Oak decline in the Krotoszyn Forest District: Oak decline in Europe. Pro- 
ceedings of the International Symposium. Kórnik (ed. by R Siwecki \& W Liese) PWRiL, Poznań.

Franklin J, Serra-Diaz JM, Syphard AD \& Regan HM (2016) Global change and terrestrial plant community dynamics. Proceedings of the National Academy of Sciences of the United States of America 113: 3725-3734.

Haines LM, O’Brien TE \& Clarke GPY (2004) Kurtosis and curvature measures for nonlinear regression models. Statistica Sinica 14: 547-570.

Hilli A, Hokkanen T, Hyvonen J \& Sutinen ML (2008) Long-term variation in Scots pine seed crop size and quality in northern Finland. Scandinavian Journal Of Forest Research 23: 395-403. doi:10.1080/02827580802334217.

Hougaard P (1982) Parameterizations of nonlinear models. Journal of the Royal Statistical Society, Series B 44: 244-252.

Hougaard P (1985) The appropriateness of the asymptotic distribution in a nonlinear regression model in relation to curvature. Journal of the Royal Statistical Society, Series B 47: 103-114.

Johnson PS, Shifley SR \& Rogers R (2009) The ecology and silviculture of oaks. 2nd ed. CAB International.

Joseph HC (1929) Germination and vitality of birch seeds. Botanical Gazette 87: 127-151.

Kantorowicz W (2000) Half century of seed years in major tree species in Poland. Silvae Genetica 49: 245-249.

Kottek M, Grieser J, Beck C, Rudolf B \& Rubel F (2006) World map of Köppen-Geiger climate classification updated. Meteorologische Zeitschrift 15: 259-263.

Ligot G, Balandier P, Fayolle A, Lejeune P \& Claessens H (2013) Height competition between Quercus petraea and Fagus sylvatica natural regeneration in mixed and uneven-aged stands. Forest Ecology and Management 304: 391-98. doi:10.1016/j. foreco.2013.05.050.

Marquardt DW (1963) An algorithm for least squares estimation of nonlinear parameters. Journal of the Society of Industrial Applied Mathematics 11: 431-441.

McVean DN (1955) Ecology of Alnus glutinosa (L.) Gaertn. II. Seed distribution and germination. Journal of Ecology 43: 61-71.

Mondoni A, Rossi G, Orsenigo S \& Probert RJ (2012) Climate warming could shift the timing of seed germination in alpine plants. Annals of Botany 110: 155-164. doi:10.1093/aob/mcs097.

Norden N, Daws MI, Antoine C, Gonzalez MA, Garwood NC \& Chave J (2009) The relationship between seed mass and mean time to germination for 1037 tree species across five tropical forests. Functional Ecology 23: 203-210. doi:10.1111/ j.1365-2435.2008.01477.x.
Nowakowska JA, Oszako T, Bieniek J \& Rakowski K (2007) Genetic characterization in relation to the health state of oak populations in the elblacki and krotoszyński regions of Poland. Leśne Prace Badawcze 3: 33-51.

Olson DF Jr (1974) Quercus L. Oak. USDA Forest Service Agriculture Handbook 450. USDA Forest Service, Wshington, DC.

Oszako T (2007) Przyczyny masowego zamierania drzewostanów dębowych. Sylwan 6: 62-72.

Ratkowsky DA (1983) Nonlinear regression modelling, Marcel Dekker, New York.

Ratkowsky DA (1990) Handbook of nonlinear regression models. Marcel Dekker, New York.

Ratkowsky DA (1993) Principles of nonlinear regression modelling. Journal of Industrial Microbiology 12: 195-199. doi:10.1007/BF01584190.

Ratkowsky DA \& Reddy GVP (2017) Empirical model with excellent statistical properties for describing temperature-dependent developmental rates of insects and mites. Annals of the Entomological Society of America 110: 302-309. doi:10.1093/ aesa/saw098.

Saatkamp A, Cochrane A, Commander L, Guja LK, Jimenez-Alfaro B, Larson J, Nicotra A, Poschlod P, Silveira FAO, Cross AT, Dalziell EL, Dickie J, Erickson TE, Fidelis A, Fuchs A, Golos PJ, Hope M, Lewandrowski W, Merritt DJ, Miller BP, Miller RG, Offord CA, Ooi MKJ, Satyanti A, Sommerville KD, Tangney R, Tomlinson S, Turner S \& Walck JL (2019) A research agenda for seed-trait functional ecology. New Phytologist 221: 1764-1775. doi:10.1111/nph.15502.

Sahlén K \& Bergsten U (1994) Predicting anatomical maturity of Pinus sylvestris L. seeds in northern Fennoscandia. Scandinavian Journal of Forest Research 9: 154-157. doi:10.1080/02827589409382825.

SAS Institute (2017) Inc. SAS/STAT 14.3 User's Guide; SAS Institute Inc.: Cary, NC, USA.

Shelton MG \& Cain MD (2000) Regenerating uneven-aged stands of loblolly and shortleaf pines: The current state of knowledge. Forest Ecology and Management 129: 177-193.

Schwarz GE (1978) Estimating the dimension of a model. Annals of Statistics 6: 461-464. doi:10.1214/aos/1176344136.

Suszka B, Muller C \& Bonnet-Masimbert M (1996) Seeds of forest broadleaves from harvest to sowing. INRA Editions, Paris.

Suszka B (2006) Generative propagation: Dęby Quercus robur L.; Q. petraea (Matt.) Liebl. Nasze Drzewa Leśne (ed. by W Bugała) Bogucki Wydawnictwo Naukowe, Poznań.

Tjørve E \& Tjørve KMC (2010) A unified approach to the Richards-model family for use in growth analyses: why we need only two model forms. 
Journal of Theoretical Biology 267: 417-425. doi:10.1016/j.jtbi.2010.09.008 PMID: 20831877.

Tjørve KMC \& Tjørve E (2017a) The use of Gompertz models in growth analyses, and new Gompertz-model approach: An addition to the Unified-Richards family. PLoS ONE 12: e0178691. doi:10.1371/journal.pone.0178691.

Tjørve KMC \& Tjørve E (2017b) A proposed family of Unified models for sigmoidal growth. Ecological Modellling 359: 117-127. doi:10.1016/j. ecolmodel.2017.05.008.

Ukalska J \& Jastrzębowski S (2019) Sigmoid growth curves, a new approach for study the dynamics of the epicotyl emergence of oak. Folia Forestalia Polonica, Series A - Forestry 61:30-41. doi:10.2478/ ffp-2019-0003.

Vrána J, Remeš V, Matysioková B, Tjørve KM \& Tjørve E (2019) Choosing the right sigmoid growth function using the unified-models approach. Ibis 161: 13-26. doi:10.1111/ibi.12592.

Vranckx G \& Vandelook F (2012) A season- and gap-detection mechanism regulates seed germination of two temperate forest pioneers. Plant Biology 14: 481-490. doi:10.1111/j.14388677.2011.00515.x.

Walck JL, Hidayati SN, Kingsley DW, Thompson K \& Poschlod P (2011) Climate change and plant regeneration from seed. Global Change Biology 17: 2145-2161. doi:10.1111/j.13652486.2010.02368.x.

Zwietering $\mathrm{MH}$, Jongenburger I, Rombouts FM \& van't Riet K (1990) Modeling of the Bacterial Growth Curve. Applied and Environmental Microbiology 56: 1875-1881. 